\title{
Venovenous extracorporeal membrane oxygenation in a patient with acute respiratory distress syndrome caused by drowning
}

\section{Marijan Pašalič ${ }^{\star}$ Boško Skorić, Maja Čikeš, Daniel Lovrić, Jana Ljubas Maček, (1) Hrvoje Jurin, Jure Samardžić, Joško Bulum, Davor Miličić}

University of Zagreb School of Medicine, University Hospital Centre Zagreb, Zagreb, Croatia
RECEIVED:

February 4, 2018

ACCEPTED:

February 10, 2018

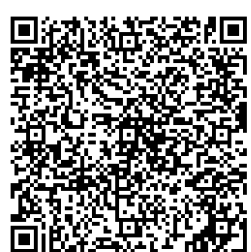

KEYWORDS: venovenous extracorporeal membrane oxygenation, drowning, acute respiratory distress syndrome.

CITATION: Cardiol Croat. 2018;13(1-2):51-52. | https://doi.org/10.15836/ccar2018.51

*ADDRESS FOR CORRESPONDENCE: Marijan Pašalić, Klinički bolnički centar Zagreb, Kišpatićeva 12, HR-10000 Zagreb, Croatia. / Phone: +385-1-2367-467 / E-mail: marijan.pasalic@yahoo.com

ORCID: Marijan Pašalić, http://orcid.org/0000-0002-3197-2190 • Boško Skorić, http://orcid.org/0000-0001-5979-2346 Maja Čikeš, http://orcid.org/0000-0002-4772-5549 • Daniel Lovrić, http://orcid.org/0000-0002-5052-6559 Jana Ljubas, Maček http://orcid.org/0000-0001-7171-2206 • Hrvoje Jurin, http://orcid.org/0000-0002-2599-553X Jure Samardžić, http://orcid.org/0000-0002-9346-6402 • Joško Bulum, http://orcid.org/0000-0002-1482-6503 Davor Miličić, http://orcid.org/0000-0001-9101-1570

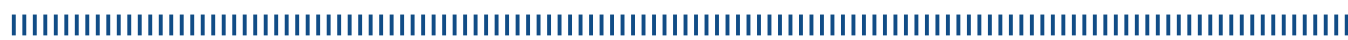

Introduction: Benefits of venovenous extracorporeal membrane oxygenation (VV-ECMO) in patients with severe acute respiratory failure (RF) have been identified in different trials ${ }^{1}$. Due to surfactant washout, drowning often results in acute respiratory distress syndrome (ARDS), which remains the most important cause of death in those patients surviving the transfer to hospital.

Case report: 32-year-old male patient with no prior medical history presented to our Emergency Department following drowning and a successful resuscitation. He was found submerged in the pool just a couple of minutes after being seen conscious and swimming. Lifeguard on duty pulled him out of the pool and started cardiopulmonary resuscitation. Upon the arrival of Emergency Medical Service, patient had a pulse and was breathing spontaneously, but was exhibiting grand mal seizures and not recovering consciousness. In the emergency department he was put on mechanical ventilation (MV) due to global RF and in the Coronary Care Unit therapeutic hypothermia (TH) was started. Urgent diagnostics was performed and no signs of stroke, coronary artery disease, pulmonary embolism or significant electrolyte imbalance were detected. 12-lead ECG and echocardiography showed no abnormal findings despite severe respiratory acidosis. Due to signs of ARDS (Figure $\mathbf{1}$ ) and worsening RF in
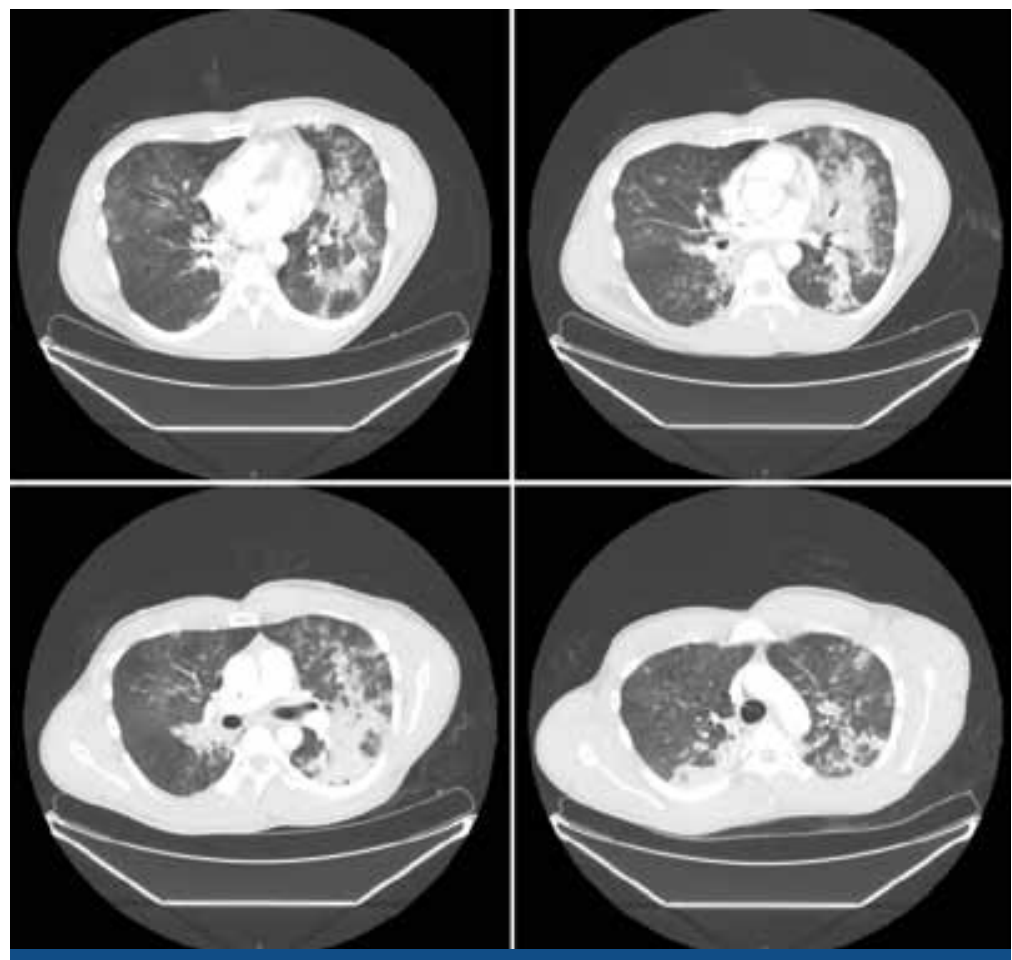

FIGURE 1. MSCT findings showing diffuse pulmonary (parenchimal) infiltrates and radiologic signs of acute respiratory distress syndrome. 
spite of increasing MV support, VV ECMO implantation was indicated. It was successfully conducted in the early period ( $<3$ hours) in order to achieve rapid normalization of blood gas levels and optimal conditions for neurologic recovery. Considering profuse aspiration, ceftriaxone and clindamycin were initiated. Following the 24 hours protocol for TH and discontinuation of sedation, patient gradually recovered consciousness. Due to persistent diffuse pulmonary infiltrates and detection of Pseudomonas in endotracheal aspirate samples, cefepime and methylprednisolone were administered. In the following days X-rays showed resolution of ARDS (Figure 2) and patient's respiratory function significantly improved. Hence, he was successfully weaned of ECMO ( $5^{\text {th }}$ day) and of MV ( $8^{\text {th }}$ day). He exhibited no signs of neurologic deficit and was rapidly mobilized. Finally, on the $21^{\text {st }}$ day he was discharged home.

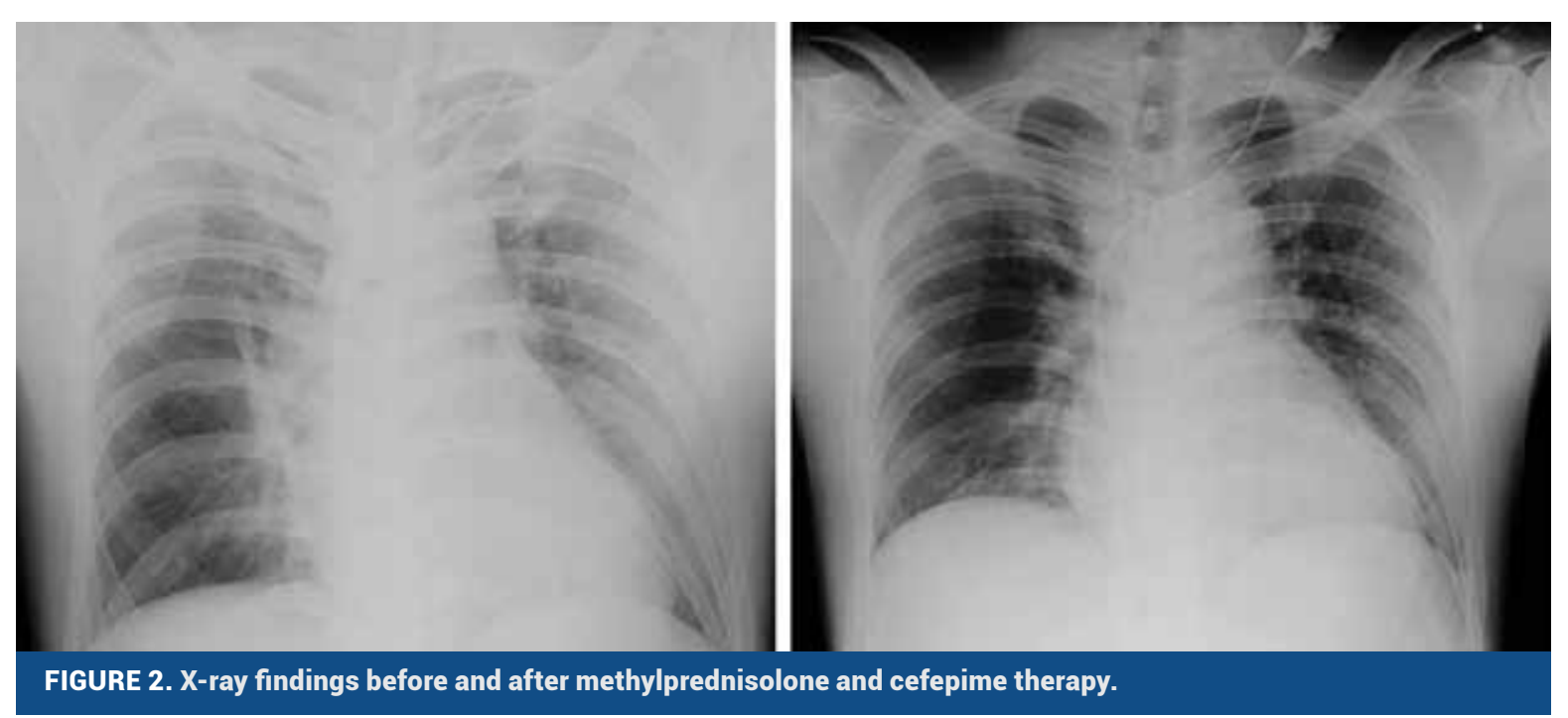

Conclusion: Our case report recognizes the potential life-saving role of VV-ECMO in treating drowning patients with severe ARDS. Hence, the use of ECMO should be beared in mind as a treatment modality in all drowning victims.

1. Peek GJ, Mugford M, Tiruvoipati R, Wilson A, Allen E, Thalanany MM, et al; CESAR trial collaboration. Efficacy and economic assessment of conventional ventilatory support versus extracorporeal membrane oxygenation for severe adult respiratory failure (CESAR): a multicentre randomised controlled trial. Lancet. 2009 0ct 17;374(9698):1351-63. https://doi.org/10.1016/S0140-6736(09)61069-2 